COMMENT. The differentiating factors for ADEM and MS outlined above are useful when considered as a group of presenting characteristics, but individually their value is limited. In an analysis of initial MRI findings predictive of a second attack of acute CNS inflammatory demyelination in 116 children, Mikaeloff et al found that the risk of MS was significantly higher in patients with corpus callosal lesions, whereas basal ganglia lesions were equally frequent in monophasic (ADEM) and recurrent (MS) disease (Brain 2004;127:1942-1947; Ped Neur Briefs 2004;18:65-66). Tenembaum et al (2002) found relapses and MS in $10 \%$ cases initially diagnosed as ADEM; residual disability was not related to MRI findings at onset, but it was correlated with the occurrence of optic neuritis (Ped Neur Briefs 2002;16:81).

\title{
ATTENTION DEFICIT HYPERACTIVITY DISORDER
}

\section{LONG-TERM EFFECTS OF ADDERALL XR IN ADHD}

The long-term tolerability and effectiveness of extended release mixed amphetamine salts (Adderall XR) in children with attention deficit hyperactivity disorder (ADHD) were evaluated in a 24-month, multicenter, open-label extension of 2 placebo-controlled studies at UCLA, Massachusetts General Hospital, UC-Irvine, Maitland, FL, and Shire Pharmaceutical, Wayne, PA. The initial dose of Adderall XR was $10 \mathrm{mg}$ daily in 568 children, aged 6-12 years, and was increased by $10 \mathrm{mg}$ weekly to optimal effective levels (maximum $30 \mathrm{mg} / \mathrm{d}$ ). Quarterly Conners Global Index Scale, Parent version (CGIS-P) was used to assess effectiveness, and adverse events, physical examinations, and laboratory tests were monitored to assess tolerability. Significant improvements $(>30 \%, \mathrm{p}<0.001)$ in CGIS-P scores were maintained through the trial, and treatment was generally well tolerated. Adverse events $(\mathrm{AE})$ included headache $(15 \%)$, anorexia $(15 \%)$, and insomnia $(11 \%) ; 15 \%$ withdrew from the study because of $\mathrm{AE}$ (weight loss, anorexia, insomnia, depression, and emotional lability). Serious $\mathrm{AE}$ were reported in 18 subjects (3\%); only 2, both convulsions, were judged possibly drug-related, at doses of 10 and $20 \mathrm{mg} / \mathrm{d}$. None required subsequent treatment with anticonvulsants. Mean systolic blood pressure increased by $3.5 \mathrm{mmHg}$, diastolic by $2.6 \mathrm{mmHg}$, pulse by 3.4 beats per min. (Changes in vital signs, ECG, and cardiovascular-related AEs to be reported later). (McGough JJ, Biederman J, Wigal SB et al. Long-term tolerahility and effectiveness of once-daily mixed amphetamine salts (1dderall XR) in children with ADHD. J Am Acad Child Adolescent Psychiatry June 2005;44:530538). (Reprints: Dr McGough, 300 UCLA Medical Plaza, Suite 1414, Los Angeles, CA 90095).

COMMENT. This paper is something of a cliff-hanger. The promise of a second installment in a subsequent publication is frustrating. The effectiveness and general tolerability of Adderall XR is well known, but answers to the concerns regarding cardiovascular events are anxiously awaited. Hopefully, we can expect this report soon.

Atomoxetine-induced blood pressure increase. A significant elevation in blood pressure is noted in 3 adolescent boys while taking doses of $80 \mathrm{mg} /$ day atomoxetine (Dworkin N. J Am Acad Child Adolesc Psychiatry June 2005;44:510). Other drugs were given in combination, compromising the significance of the report, but our own practice of monitoring BP, pulse, height, and weight regularly in ADHD patients will be continued. 